УДК 615.322:582.929:547.98.062:543.422'551

\title{
СОДЕРЖАНИЕ ДУБИЛЬНЫХ ВЕЩЕСТВ В СПИРТОВОМ ИЗВЛЕЧЕНИИ TPAВЫ ДУБРОВНИКА БЕЛОГО (TEUCRIUM POLIUM L.) И ОПРЕДЕЛЕНИЕ ЕГО АНТИОКСИДАНТНОЙ АКТИВНОСТИ
}

\author{
(C) Н.Г. Рудакова , А.Б. Дмитриев, О.И. Попова
}

Пятигорский медико-фрармацевтический институт - филиал
Волгоградского государственного медицинского университета,
ул. Калинина, 11, Пятигорск, 357500 (Россия), e-mail: Rudakovaya@mail.ru

Исследовано содержание дубильных веществ в траве дубровника белого. Содержание дубильных веществ в траве дубровника белого было определено различными методами. Показано, что наиболее подходящими методами определения дубильных веществ является кулонометрия и спектрофотометрия. Определена антиоксидантная активность спиртового извлечения травы методом кулонометрии.

Ключевые слова: Teucrium polium L., дубильные вещества, перманганатометрический, спектрофотометрический, кулонометрический методы, антиоксидантная активность.

\section{Введение}

Род Teucrium L. (Дубровник) семейства яснотковые (Lamiaceae) насчитывает около 340 видов, распространенных по всему миру [1]. На территории России и стран СНГ род Teucrium L. представлен 26 видами, из них на Кавказе произрастает 13 видов [2].

Объектом исследования выбран дубровник белый (Teucrium polium L.), представляющий собой многолетнее травянистое растение, высотой 30-40 см, с деревянистым корнем. Стебли многочисленные, твердые, густовато-опушенные, седоватые или иногда снежно-белые, на верхушке щитковидно-ветвистые. Листья супротивные, сидячие, ланцетной формы, клиновидно суженные у основания, на верхушке тупые, по всему краю неглубоко городчато-зубчатые, с обеих сторон войлочно-опушенные. Соцветия густые, головчатые, шаровидные, на коротких цветоносах, состоящие из сильно сближенных ложных мутовок; цветки почти сидячие, 5-8 мм длиной, беловатые или желтоватые; чашечка коротко трубчато-колокольчатая, бороздчатая, с почти одинаковыми коротко треугольными, туповатыми зубцами значительно короче трубки. Плод - ценобий.

Имеются сведения об использовании надземных частей дубровника белого в виде водного, спиртового и водно-спиртового извлечений в качестве противовоспалительного, гипохолестеринемического, противоопухолевого, гепатопротективного и антиоксидантного средств [3-6].

Данные виды фармакологической активности реализуются за счет определенного набора антиоксидантных веществ: витаминов, фенольных соединений, которые обладают низкой токсичностью и мягким воздействием на организм.

Дмитриев Александр Борисович - доцент, кандидат химических наук кафедры аналитической химии, e-mail: abdmitr2006@yandex.ru

Попова Ольга Ивановна - профессор кафедры фармакогнозии, доктор фармацевтических наук, e-mail: beegeeslover@mail.ru

Рудакова Юлия Георгиевна - аспирант кафедры фармакогнозия, e-mail: Rudakovaya@mail.ru
В литературе имеются противоречивые данные о качественном и количественном составе биологически-активных веществ (БАВ), согласно которым в дубровнике белом содержатся ди- и тритерпеновые соединения и фенольные соединения (флавоноиды, фенолокислоты, дубильные вещества, кума-

\footnotetext{
* Автор, с которым следует вести переписку.
} 
рины) [7]. Однако сведения о количественном содержании фенольных соединений в дубровнике белом отсутствуют.

Цель настоящего исследования - определение дубильных веществ в спиртовом извлечении из травы дубровника белого и определение его антиоксидантной активности.

\section{Экспериментальная часть}

В качестве объекта исследования использовали траву дубровника белого, которая представляет собой цветоносные верхушки побегов длиной до 15 см и отдельные листья. Образцы сырья собраны в окрестностях Пятигорска на юго-восточных склонах горы Машук и горы Бештау в фазу цветения в 2012 г. Растительное сырье собирали в сухую, ясную погоду в средней части склона на открытых участках и сушили воздушно-теневым способом при температуре $20-25^{\circ} \mathrm{C}$. Сырье представляет собой смесь цельных кусочков или частично измельченных веточек, листьев, кусочков стеблей толщиной до 0,3 см и цветков. Образцы измельчали до размера частиц, проходящих сквозь сито с диаметром отверстий 2 мм.

Для проведения анализа исследуемого сырья была взята аналитическая проба в соответствии с ОФС 42-0013-03 «Правила приемки лекарственного растительного сырья и методы отбора проб».

Извлечение получали по следующей методике. Около 2,0 г (точная навеска) измельченного сырья помещали в плоскодонную колбу со шлифом вместимостью 100 мл. Прибавляли 50 мл спирта этилового 50\%, присоединяли к обратному холодильнику и нагревали на кипящей водяной бане в течение 1 ч. После чего охлаждали до комнатной температуры и фильтровали в мерную колбу вместимостью 50 мл через бумажный фильтр так, чтобы частицы сырья не попали в извлечение, и доводили спиртом этиловым $50 \%$ до метки.

Для определения содержания дубильных веществ в полученном извлечении использовали 3 метода: кулонометрия, спектрофотометрия и титрование раствором калия перманганата.

Определение дубильных веществ методом перманганатометрии осуществляли по методике ГФ XI [8]. 10 мл полученного извлечения отбирали пипеткой в колбу вместимостью 250 мл, прибавляли 100 мл воды, 10 мл 0,1\% раствора индигосульфокислоты и титровали при перемешивании 0,02 М раствором калия перманганата до золотисто-желтого окрашивания. Параллельно проводили контрольный опыт. Общее содержание веществ, окисляющихся при титровании раствором калия перманганата (Х\%), в процентах в пересчете на воздушно-сухое сырье вычисляли по формуле 1:

$$
X \%=\frac{\left(V_{1}-V_{0}\right) \cdot 0,004157 \cdot 50 \cdot 100 \cdot 100}{m \cdot V_{a} \cdot(100-W)}
$$

где $\mathrm{V}_{1}$ - объем раствора перманганата калия (0,02 моль/л), израсходованного на титрование извлечения, мл; $\mathrm{V}_{0}$ - объем раствора перманганата калия $(0,02$ моль/л), израсходованного на титрование в контрольном опыте, мл; 0,004157 - количество дубильных веществ, соответствующее 1 мл раствора перманганата калия (0,02 моль/л) (в пересчете на танин), г; m - масса сырья, г; 50 - общий объем извлечения, мл; $\mathrm{V}_{a}-$ объем извлечения, взятого для титрования, мл; W - потеря в массе при высушивании сырья, \%. Объем раствора калия перманганата, пошедший на титрование в контрольном опыте, составил 0,4 мл.

Кулонометрическое титрование осуществляли по методике С.Г. Абдуллиной [9]. Кулонометрическое титрование проводили при постоянной силе тока 5 мА на кулонометре «Эксперт-006» с бипотенциометрической индикацией конечной точки титрования (КТТ) (I = 2 мкА). Анодная камера отделялась от катодной полупроницаемой мембраной. Генерацию титранта проводили из $0,1 \mathrm{M}$ калия йодида в фосфатном буферном растворе с рН 9,8. Генераторным и вспомогательным электродами служили платиновые спирали. Аликвоту 0,5 мл полученного извлечения вносили в ячейку для кулонометрического титрования, подобрав ее с таким расчетом, чтобы на титрование затрачивалось не более 5 мин. Содержание дубильных веществ в пересчете на танин (Х\%) рассчитывали по формуле 2 :

$$
X \%=\frac{I \cdot t \cdot 41,57 \cdot 50 \cdot 100 \cdot 100}{F \cdot m \cdot V_{a} \cdot(100-W)},
$$


где I - сила тока, A; t - время достижения конечной точки титрования, c; 41,57 - условная величина молярной массы эквивалента танина, г/моль; $\mathrm{m}$ - навеска сырья, г; $\mathrm{V}_{a}$ - объем аликвоты, вводимый в кулонометрическую ячейку, мл; W - потеря в массе при высушивании, \%; F - постоянная Фарадея 96485 Кл/моль.

Спектрофотометрическое определение дубильных веществ осуществляли по методике, описанной К.Н. Разарёновой [10]. Однако нами она была модифицирована следующим образом: 1 мл полученного извлечения помещали в мерную колбу вместимостью 100 мл и доводили спиртом этиловым $50 \%$ до метки. Оптическую плотность полученного раствора измеряли на спектрофотометре «СФ-2000» в кювете с толщиной слоя 10 мм в диапазоне длин волн 250-350 нм относительно спирта этилового 50\%. Водноспиртовое извлечение имело максимум светопоглощения при длине волны $283 \pm 2$ нм. Параллельно измеряли оптическую плотность раствора стандартного образца (CO) танина.

Приготовление раствора СО танина. Около 0,1 г СО танина (точная навеска), предварительно высушенного при температуре $100-105^{\circ} \mathrm{C}$ до постоянной массы, помещали в мерную колбу вместимостью 100 мл, растворяли в 80 мл спирта этилового 50\%, доводили объем раствора тем же растворителем до метки и перемешивали. 1 мл раствора помещали в мерную колбу вместимостью 50 мл, доводили объем раствора спиртом этиловым 50\% до метки и перемешивали.

Содержание дубильных веществ в пересчете на танин (Х\%) рассчитывали по формуле 3:

$$
X \%=\frac{A_{x} \cdot m_{c m} \cdot V_{c m} \cdot W_{x} \cdot 100}{A_{c m} \cdot m_{x} \cdot V_{x} \cdot W_{c m}} \cdot \frac{100}{(100-W)},
$$

где $\mathrm{A}_{\text {ст }}$ и $\mathrm{A}_{\mathrm{x}}$ - значения оптических плотностей растворов СО танина и анализируемого образца соответст-

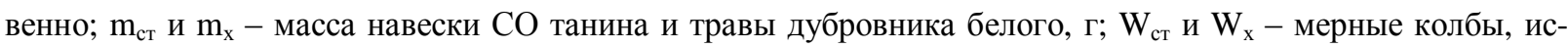
пользуемые для разведения навесок $\mathrm{CO}$ танина и анализируемого образца, мл; $\mathrm{V}_{\text {ст }}$ и $\mathrm{V}_{\mathrm{x}}$ - аликвоты растворов СО танина и анализируемого образца, мл; W - потеря в массе при высушивании сырья, \%.

Математическую обработку экспериментальных данных проводили методами дисперсионного анализа и интервальной оценки параметров распределения при помощи t-критерия.

Антиоксидантную активность определяли методом кулонометрического титрования электрогенерированным бромом [11]. Измерения проводили при постоянной силе тока 5 мА на кулонометре «Эксперт-006» с биамперометрической индикацией КТТ ( $\Delta \mathrm{E}=500 \mathrm{MB})$. Анодная камера отделялась от катодной полупроницаемой мембраной. Генерацию титранта проводили из 0,5 М калия бромида в 1,0 М растворе серной кислоты. Генераторным и вспомогательным электродами служили платиновые спирали. Аликвоту извлечения 0,5 мл, вносимую в ячейку для кулонометрического титрования, подбирали с таким расчетом, чтобы время титрования не превышало 7 мин. Стандартным веществом для определения антиоксидантной активности был выбран рутин, для которого число электронов, участвующих в реакции с титрантом, равно $8[12,13,16]$.

По результатам анализа рассчитывали суммарное содержание свободных антиоксидантов в исследуемом извлечении в граммах рутина на 100 г абсолютно сухого образца.

\section{Результаты и их обсуждение}

В результате спектрофотометрического определения содержания дубильных веществ в исследуемом извлечении дубровника белого было выявлено, что максимум длины волны исследуемого извлечения на-

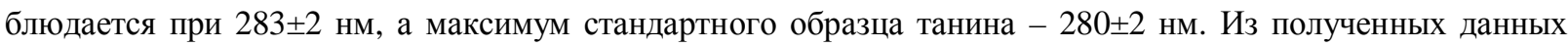
видно, что максимум длины волны изучаемого извлечения практически совпадает с максимумом длины волны стандартного образца танина.

Результаты количественного определения содержания дубильных веществ в траве дубровника белого представлены в таблице 1.

Таблица 1. Результаты определения дубильных веществ

\begin{tabular}{c|l|c|c|c|c|c|cc}
\hline № & \multicolumn{1}{|c|}{ Метод } & $\mathrm{n}$ & $\overline{\mathrm{x}}$ & $\mathrm{S}^{2}$ & $\mathrm{~S}$ & $\Delta \mathrm{x}$ & $\mathrm{E} \%$ \\
\hline 1 & Перманганатометрия & 4 & 7,87 & 0,0064 & 0,08 & 0,11 & 1,4 \\
2 & Кулонометрия & 7 & 3,70 & 0,0484 & 0,22 & 0,2 & 5,4 \\
3 & Спектрофотометрия & 4 & 3,47 & 0,01 & 0,1 & 0,14 & 4,0 \\
\hline
\end{tabular}


Данные статистической обработки показали, что использованные методики характеризуются приемлемой относительной погрешностью. Полученные результаты показывают, что кулонометрический и спектрофотометрический методы дают близкие значения, а перманганатометрический метод значительно большие. В связи с этим мы провели сравнение полученных результатов с использованием методов математической статистики (табл. 2).

Сравнение по критерию Фишера $(\mathrm{F})$ показывает незначимое различие дисперсий, так как $\mathrm{F}_{\text {рассчитанное }}$

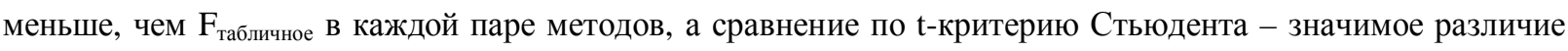
результатов метода перманганатометрии с кулонометрией и спектрофотометрией, и незначимость различия $\mathrm{X}$ для кулонометрии и спектрофотометрии.

Метод перманганатометрии показал завышенные результаты в определении дубильных веществ, которые обусловлены следующим: трудность фиксации конечной точки титрования, возможность окисления перманганатом других фенольных соединений, зависимость результатов от скорости перемешивания титруемого раствора и освещения $[14,15]$. Кроме того, недостатком данной методики является необходимость предварительной стандартизации титранта и проведение контрольного опыта.

В результате эксперимента была определена антиоксидантная активность спиртового извлечения травы дубровника белого. Результаты определения антиоксидантной активности представлены в таблице 3.

Антиоксидантная активность дубровника белого составила 9,6 г рутина на 100 г абсолютно сухого образца. Сравнение антиоксидантной активности дубровника белого с антиоксидантной активностью некоторых видов лекарственного растительного сырья показывает, что последние намного уступают по данному показателю. Так, антиоксидантаная активность водного эктракта боярышника алма-атинского (свежие пло-

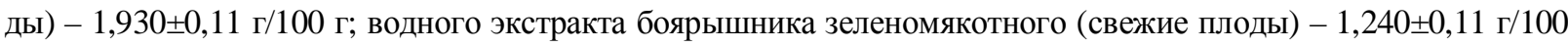

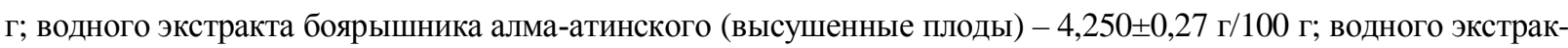

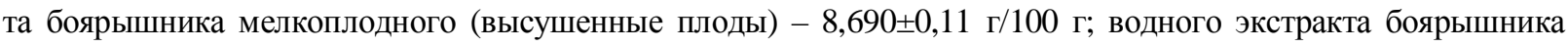

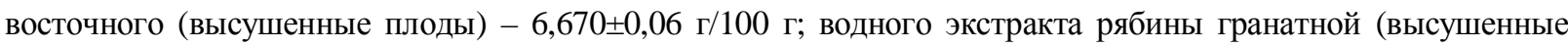

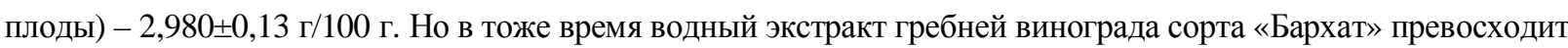
по антиоксидантной активности спиртовое извлечение из травы дубровника белого. Показатель антиокси-

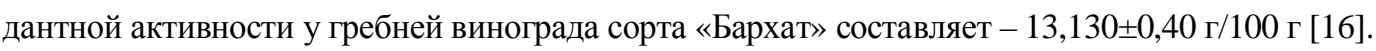

Таблица 2. Сравнение методов определения дубильных веществ

\begin{tabular}{l|c|c|c|cc}
\hline \multicolumn{1}{c|}{ Сравнение методов } & $\mathrm{F}$ & $\mathrm{F}_{\text {табл }}$ & $\mathrm{t}$ & $\mathrm{t}_{\text {табл }}$ \\
\hline Перманганатометрия - кулонометрия & 7,56 & 8,94 & 36,75 & 2,26 \\
Перманганатометрия - спектрофотометрия & 1,56 & 9,28 & 69,03 & 2,45 \\
Кулонометрия - спектрофотометрия & 4,84 & 8,94 & 1,95 & 2,26 \\
\hline
\end{tabular}

Таблица 3. Антиоксидантная активность спиртового извлечения травы дубровника белого

\begin{tabular}{l|c|c|c|c|c|c|c}
\hline Метрологические характеристики & $\mathrm{n}$ & $\overline{\mathrm{x}}$ & $\mathrm{S}$ & $\mathrm{S}_{\mathrm{x}}$ & $\Delta \mathrm{x}$ & $\mathrm{x} \pm \Delta \mathrm{x}$ & $\mathrm{E} \%$ \\
\cline { 2 - 9 } & 5 & 9,6 & 0,22 & 0,11 & 0,28 & $9,6 \pm 0,28$ & 2,9 \\
\hline
\end{tabular}

\section{Bblвodbl}

Содержание дубильных веществ в траве дубровника белого определено тремя методами. Полученные данные показывают, что метод перманганатометрии дает завышенные результаты в определении дубильных веществ. Таким образом, оптимальными методами для количественного определения дубильных веществ являются кулонометрический и спектрофотометрический методы. Полученное суммарное содержание свободных антиоксидантов в исследуемом извлечении травы дубровника белого составило 9,6 г рутина на 100 г абсолютно сухого образца.

\section{Список литературы:}

1. Tutin T.G., Heywood V.H., Burges N.A. et al. In Flora Europaea // Cambridge Universiti Press. 1972. Vol. 3. P. 425.

2. Черепанов С.К. Сосудистые растения России и сопредельных государств (в пределах бывшего СССР). СПб., 1995. $960 \mathrm{c}$.

3. Чачоян А.А., Алексанян Р.А., Галстян А.М. и др. Исследование биологической активности дубровника беловойлочного (Teucrium polium L., Lamiaceae) // Растительные ресурсы. 1992. Т. 3, №6. С. 81-85. 
4. Capasso F., Cerri R., Morrica P., Senatore F. Chemical composition and anti-inflammatory activity of analcoholic extract of Teucrium polium L. // Boll. Soc. Ital. Biol. Sper. 1983. Vol. 59, N11. Pp. 1639-1643.

5. Ilhami G., Metin U., Munir O. et al. Irfan K. Antioxidant and antimicrobial activities of Teucrium polium L. // J. Food Tech. 2003. Vol. 1, N1. Pp. 9-16.

6. Сидакова Т.М., Саджая Л.А., Сергеева Е.О., Попова О.И. Изучение влияния отвара и спиртового извлечения травы мяты длиннолистной (Mentha longifolia L.) на секрецию желчи у крыс // Вопросы биологической, медицинской и фармацевтической химии. 2011. №3. С. 30-32.

7. Bahramikia S., Yazdanparast R. Phytochemistry and Medicinal Properties of Teucrium plium L. (Lamiaceae) // Phytotherapy Research. 2012. Vol. 26, N11. Pp. 1581-1593.

8. Государственная фармакопея СССР: Общие методы анализа. М., 1987. Вып. 1. 335 с.

9. Патент № 2436084 (РФ). Способ кулонометрического определения содержания дубильных веществ в растительном сырье / С.Г. Абдуллина, Н.М. Агапова, Р.Ш. Хазиев, Г.К. Зиятдинова, Г.К. Будников // 2010. БИ. №4. C. 13-15.

10. Разарёнова К.Н., Жохова Е.В. Сравнительная оценка содержания дубильных веществ в некоторых видах рода Geranium L. флоры Северо-Запада // Химия растительного сырья. 2011. №4. С. 187-192.

11. Низамова А.М., Зиятдинова Г.К., Будников Г.К. Электрогенерированный бром-кулонометрический реагент для оценки биодоступности полифенолов // Журнал аналитической химии. 2011. Т. 66, №3. С. 308-316.

12. Зиятдинова Г.К., Низамова А.М., Будников Г.К. Гальваностатическая кулонометрия в анализе природных полифенолов и ее применение в фармации // Журнал аналитической химии. 2010. Т. 65, №11. С. 1202-1206.

13. Попова О.И., Чумакова В.В., Кодониди М.И. Изучение антиоксидантной активности извлечений травы лофанта анисового // Вопросы биологической, медицинской и фармацевтической химии. 2012, №12. С. 30-33.

14. Рудакова Ю.Г., Попова О.И. Определение дубильных веществ в траве дубровника белого (Teucrium polium L.) // Материалы IV Всерос. науч.-практ. конф. с междунар. участием. Владикавказ, 2013. С. 170-175.

15. Попова О.И., Мезенова Т.Д., Чумакова В.В. Количественное определение галловой кислоты в траве лофанта анисового // Медицинский вестник Северного Кавказа. 2010. №4(20). С. 75-76.

16. Романова Н.Г., Зеленков В.Н., Лапин А.А. Определение антиоксидантной активности плодово-ягодного сырья, гребней винограда, зеленого и черного чая // Известия ТСХА. 2011. №3. С. 163-167.

Поступило в редакциию 3 апреля 2013 г.

После переработки 11 ноября 2013 г. 
Rudakova Iu.G. ${ }^{*}$, Dmitriev A.B., Popova O.I. THE CONTENT OF TANNINS IN THE ALCOHOL EXTRACT OF THE HERB OF TEUCRIUM POLIUM L. AND DETERMINATION OF ITS ANTIOXIDANT ACTIVITY

Piatigorsky Medical and Pharmaceutical Institute - a branch of Volgograd State Medical University, Kalinina st., 11, Pyatigorsk, 357500 (Russia),e-mail: Rudakovaya@mail.ru

The content of tannins in the herb of Teucrium polium L. is investigated. The content of tannins in the herb of Teucrium polium L. was determined by different methods. There is shown the most suitable methods of tannins determination are the coulometry and the spectrophotometry. The antioxidant activity of alcohol extract by coulometry is determined. activity.

Keywords: Teucrium polium L., tannins, permanganatometric, spectrophotometric, coulometric methods, antioxidant

\section{References}

1. Tutin T.G., Heywood V.H., Burges N.A. et al. Cambridge Universiti Press, 1972, vol. 3, p. 425.

2. Cherepanov S.K. Sosudistye rasteniia Rossii i sopredel'nykh gosudarstv (v predelakh byvshego SSSR). [Vascular plants of Russia and adjacent states (the former USSR).]. St. Petersburg, 1995, 960 p. (in Russ.).

3. Chachoian A.A., Aleksanian R.A., Galstian A.M. Rastitel'nye resursy, 1992, vol. 3, no. 6, pp. 81-85. (in Russ.).

4. Capasso F., Cerri R., Morrica P., Senatore F. Boll. Soc. Ital. Biol. Sper., 1983, vol. 59, no. 11, pp. 1639-1643.

5. Ilhami G., Metin U., Munir O. et al. Irfan K. J. Food Tech., 2003, vol. 1, no. 1, pp. 9-16.

6. Sidakova T.M, Sadzhaia L.A., Sergeeva E.O., Popova O.I. Voprosy biologicheskoi, meditsinskoi i farmatsevticheskoi khimii, 2011, no. 3, pp. 30-32. (in Russ.).

7. Bahramikia S., Yazdanparast R. Phytotherapy Research., 2012, vol. 26, no. 11, pp. 1581-1593.

8. Gosudarstvennaia farmakopeia SSSR: Obshchie metody analiza. [USSR State Pharmacopoeia General methods of analysis.]. Moscow, 1987. no. 1, 335 p. (in Russ.).

9. Patent 2436084 (RU). 2010. (in Russ.).

10. Razarenova K.N., Zhokhova E.V. Khimiia rastitel'nogo syr'ia, 2011, no. 4, pp. 187-192. (in Russ.).

11. Nizamova A.M., Ziiatdinova G.K., Budnikov G.K. Zhurnal analiticheskoi khimii, 2011, vol. 66, no. 3, pp. $308-316$. (in Russ.).

12. Ziiatdinova G.K., Nizamova A.M., Budnikov G.K. Zhurnal analiticheskoi khimii, 2010, vol. 65, no. 11, pp. $1202-1206$. (in Russ.).

13. Popova O.I., Chumakova V.V., Kodonidi M.I. Voprosy biologicheskoi, meditsinskoi i farmatsevticheskoi khimii, 2012, no. 12, pp. 30-33. (in Russ.).

14. Rudakova Iu.G., Popova O.I. Materialy IV Vseros. nauch.-prakt. konf. s mezhdunar. uchastiem. [Proceedings of the IV All-Russian scientific and practical conference with international participation]. Vladikavkaz, 2013, pp. 170-175. (in Russ.).

15. Popova O.I., Mezenova T.D, Chumakova V.V. Meditsinskii vestnik Severnogo Kavkaza, 2010, no. 4(20), pp. $75-76$. (in Russ.).

16. Romanova N.G., Zelenkov V.N., Lapin A.A. Izvestiia TSKhA, 2011, no. 3, pp. 163-167. (in Russ.).

Received April 3, 2013

Revised November 11, 2013

\footnotetext{
* Corresponding author.
} 